상징과모래놀이치료, 제 8 권 제 2 호

Journal of Symbols \& Sandplay Therapy

2017, 12, Vol. 8, No. 2, 63-77.

\title{
The Effect of Parent Group Sandplay Therapy on the Nepal Earthquake Survivors: Post - Traumatic Stress Symptoms, Parenting Stress and Psychological Well - Being of Parents as well as Post - Traumatic Stress Symptoms in Children*
}

\author{
Haegi Hwang**
}

\begin{abstract}
$<$ Abstract $>$
People who have experienced property damage and loss from the Nepal earthquake in 2015 are living in a temporary tent area. These earthquake survivors experience symptoms of post-traumatic stress and exhibit altered thoughts and behaviors. This study was conducted on parents who reside in the tent city at Chuchepati and who have children aged from 7 to 17. For the group sandplay therapy program, the Impact of Events Scale-Revised, Child Report of Post-traumatic Symptoms, and the Parent Report of Post-traumatic Symptoms were administered. There were 24 individuals who agreed to participate in this study and whose child received 19 or more points from child post-traumatic symptom reports, along with 16 or more points from parent post-traumatic symptom reports, and 33 points from the IES-R. The results of this study indicate that parent group sandplay therapy is effective in reducing the symptoms of post-traumatic stress and parenting stress, and also in enhancing the psychological well-being of parents.
\end{abstract}

Keywords : group sandplay therapy, earthquake survivors, parent survivors, Nepal earthquake

* This paper is a summary of the presentation delivered at the 24th International Conference on the International Society for Sandplay Therapy (ISST) held in Hawaii, USA.

** Play Therapist, Gonggam Child Development Center, Jeonju, Korea (hyejih37@gmail.com) 
Journal of Symbols \& Sandplay Therapy, Vol.8 No.2.

\section{I . Introduction}

\section{Purpose of Research}

In April 2015, a major earthquake with a magnitude of 7.3 hit Nepal. Together with multiple aftershocks, the earthquake killed 9,000 people and injured 22,000. More than 550,000 homes were destroyed, and as a result tent cities sprang up across the country (Ministry of Home Affairs, 2015). Traumatic events like this earthquake result in symptoms of intrusion and avoidance, as well as symptoms of negative cognitive and emotional changes in relation to the traumatic event (American Psychiatric Association, 2013). Direct or indirect experiences of such disasters have a negative impact especially on the physical and emotional development of children, who have difficulty expressing their psychological and emotional stress in a verbal manner (Kang et al., 2014).

Children are a group of dependent beings; their development is largely affected by personal, environmental, social and cultural factors (Kang et al., 2011). The parent-child relationship is very important in child development. It is precisely this relationship that impacts the child's resilience either positively or negatively. Therefore, children who experience anxiety and post-traumatic symptoms after an earthquake require parents to provide nurturing in a stable manner (Correia \& Linhares, 2007). The higher the level of psychological wellbeing of a parent, the better he or she can provide stable nurturance for the child. Psychological wellbeing is the parent's level of happiness or satisfaction over life as a whole (Moon \& Lee, 2010). Parental stress is related to psychological wellbeing: poor psychological wellbeing leads to high level of parental stress. High levels of parental stress largely determine the quality of parent-child relationships as well as the child's development in terms of their emotions, personality and attitude (Lopata, 1972). So in other words, the parent's psychological wellbeing and parental stress have a great amount of influence over the child's development (Jung \& Kim, 2014).

The principal religion of Nepal is Hinduism. The Hindus believe that they should entirely surrender their life to the gods and simply accept and resign themselves to what happens in life (Shariff, 2009). The religion suppresses all forms of negative emotional expression. This means that the people of Nepal have not been free to express the 
Haegi Hwang / The Effect of Parent Group Sandplay Therapy on the Nepal Earthquake Survivors: Post-Traumatic Stress Symptoms. Parenting Stress and Psychological Well-Being of Parents as well as Post-Traumatic Stress Symptoms in Children

psychological difficulties they experienced after the earthquake. Furthermore, the family culture in Nepal emphasizes submission to authority and sacrifice on the part of women (Lee, 2015). Such a culture makes it difficult for female victims especially to adapt to the changes in their daily lives after a traumatic event like an earthquake, which further exacerbates the trauma. This can lower parents' levels of psychological wellbeing, which would negatively influence not only the parents but also their children (Jung \& Choi, 2010).

Therefore, Nepalese mothers who are particularly affected by Nepal's male-oriented family culture need sandplay therapy that helps them to express their suppressed emotions. Group sandplay therapy enables earthquake survivors to share their personal emotions and accept the emotions of others, allowing active interaction and relationship-building. Furthermore, the therapy allows survivors to externalize their problems caused by the natural disaster, helping them to resolve their conflicts and traumas.

\section{Research Questions}

1) Can the parents' group sandplay therapy reduce the symptoms of post-traumatic stress of Nepal earthquake child survivors?

2) Can the group sandplay therapy reduce the symptoms of post-traumatic stress of Nepal earthquake parent survivors?

3) Can the group sandplay therapy reduce the parenting stress of Nepal earthquake parent survivors?

4) Can the group sandplay therapy enhance the psychological well-being of Nepal earthquake parent survivors?

\section{Research object}

\section{Object of Research}

The participants were parents with children aged from 7 to 17 , who were living in a 
Journal of Symbols \& Sandplay Therapy, Vol.8 No.2.

Table 1. Socio-demographic Equivalence between the Experimental and Control Groups

\begin{tabular}{|c|c|c|c|c|}
\hline & & $\begin{array}{l}\text { Experimental group } \\
\qquad(\mathrm{N}=12)\end{array}$ & $\begin{array}{l}\text { Control group } \\
\qquad(\mathrm{N}=12)\end{array}$ & $Z$ \\
\hline & & $\mathrm{M}(\mathrm{SD})$ & $\mathrm{M}(\mathrm{SD})$ & \\
\hline \multirow{4}{*}{ Parent } & Age & $42.33(5.14)$ & $39.17(7.02)$ & -1.15 \\
\hline & Education level & $0.17(0.58)$ & $0.33(1.15)$ & 0 \\
\hline & Employment & $2.00(0.00)$ & $1.83(0.39)$ & -1.41 \\
\hline & Religion & $2.08(0.67)$ & $1.33(0.49)$ & $-2.31^{*}$ \\
\hline \multirow{3}{*}{ Child } & Age & $13.33(2.90)$ & $13.50(3.48)$ & -0.12 \\
\hline & Education level & $4.83(1.99)$ & $5.00(2.30)$ & -0.05 \\
\hline & Religion & $2.00(0.74)$ & $1.33(0.49)$ & $-2.11^{*}$ \\
\hline
\end{tabular}

${ }^{*}{ }_{p}<.05$

tent city at Chuchepati in the capital city of Kathmandu. To explain our selection process, first, we chose parents whose child scored 19 or higher on the Child Report of Post-traumatic Symptoms (CROPS), and 16 or higher on the Parent Report of Post-traumatic Stress Symptoms(PROPS). CROPS is a self-report instrument that helps assess a child's internal symptoms and PROPS is a parent's report on a child's external symptoms. Then among those chosen, we again selected 24 parents who scored 33 or higher on the Impact of Event Scale -Revised (IES-R). We divided these 24 parents into two groups randomly: 12 in the experimental group and 12 in the control group.

In terms of basic information about the participants, the average age of parents was 42 for the experimental group and 39 for the control group. The average age of children for both groups was 13. The duration of residence in the tent city was 16 months for all participants. All parents have remained unemployed since the earthquake. Everyone had experienced the death and injury of family members, relatives or neighbors. And everyone except two people, one in the experimental group and one in the control group, have never received a proper school education. 
Haegi Hwang / The Effect of Parent Group Sandplay Therapy on the Nepal Earthquake Survivors: Post-Traumatic Stress Symptoms, Parenting Stress and Psychological Well-Being of Parents as well as Post-Traumatic Stress Symptoms in Children

\section{The Questionnaire}

To further minimize possible differences in language expression, we arranged an orientation session with a local coordinator, an interpreter and local surveyors to whom we explained the contents of the questionnaire and our research ethics and research objective. The local surveyors read the questionnaire in the Nepalese language to the participants, who answered verbally.

\section{Research Tools}

As tools employed in this study were written either in Korean or English, a Korean professor of psychotherapy and a Nepalese professor of child welfare examined the tools together prior to the study in order to minimize any cultural or language differences. The final language chosen for the tools was English.

\section{1) The Child Report of Post-traumatic Symptoms (CROPS) / the Parent Report} of Post-traumatic Symptoms (PROPS)

Both CROPS and PROPS were developed to assess post-traumatic symptoms in children, based on the existing diagnostic criteria of PTSD. The CROPS survey is a self-report measure for children with 26 items related to post-traumatic symptoms. It asks children to report how often they have experienced each item in the past week. The CROPS survey is a 32-item parent-report measure that assesses their children's post-traumatic symptoms. While CROPS is focused more on internal symptoms like thoughts and feelings, PROPS is focused more on observable, external behaviors. The cut-off points are 19 for CROPS and 16 for PROPS. Points higher than the cut-off indicate that the child experiences post-traumatic

Table 2. Internal Consistency of the CROPS and the PROPS

\begin{tabular}{ccc} 
& Number of items & Cronbach's $a$ \\
\hline CROPS & 26 & .79 \\
PROPS & 32 & .64 \\
\hline
\end{tabular}


Journal of Symbols \& Sandplay Therapy, Vol.8 No.2.

symptoms (Greenwald \& Rubin, 1999). The Cronbach's alpha was .79 for CROPS and .64 for PROPS.

\section{2) The Impact of Event-Revised(IES-R)}

The IES- $\mathrm{R}$ is a 22-item self-report measure that assesses subjective distress caused by traumatic events. It is a revised version of the older version, the 15-item IES (Horowitz et al., 1979). The IES-R contains seven additional items related to the hyperarousal symptoms of PTSD, which were not included in the original IES. Items correspond directly to 14 of the 17 DSM-IV symptoms of PTSD. Respondents are asked to identify a specific stressful life event and then indicate how much they were distress or bothered during the past seven days by each "difficulty" listed (Weiss \& Marmer, 1997). The cut-off point for the selection of participants was 33 or higher, which indicates clinically significant PTSD (Weiss, 2007). In this study, the Cronbach's alpha for this scale was .80 .

Table 3. Internal Consistency and Subscales of the IES-R

\begin{tabular}{cccc}
\hline Subscales & Number of items & Composition of items & Cronbach's $a$ \\
\hline Avoidance & 8 & $5,7,8,11,12,13,17,22$ & .66 \\
Intrusion & 8 & $1,2,3,6,9,14,16,20$ & .65 \\
Hyperarousal & 6 & $4,10,15,18,19,21$ & .71 \\
Total & 22 & - & .80 \\
\hline
\end{tabular}

\section{3) Parental Stress Scale (PSS)}

The PSS is an 18-item scale related to both positive and negative aspects of parenting, like compensation and satisfaction as well as burdens and difficulties. To be more specific, the items represent both positive and negative themes of parenthood, the positive being emotional benefits and personal development, and the negative being demands on social resources and restrictions. The higher the total score, the higher the measured level of parental stress. A higher score reflects a lower level of sensitivity toward the child, lower level of ability to respond, and lower quality of parent-child relationship (Berry \& Jones, 1995). The 
Haegi Hwang / The Effect of Parent Group Sandplay Therapy on the Nepal Earthquake Survivors: Post-Traumatic Stress Symptoms, Parenting Stress and Psychological Well-Being of Parents as well as Post-Traumatic Stress Symptoms in Children

Table 4. Internal Consistency and Subscales of the PSS

\begin{tabular}{cccc}
\hline Subscales & Number of items & Composition of items & Cronbach's $a$ \\
\hline Positive theme & 8 & $1,2,5,6,7,8,17,18$, & .64 \\
Negative theme & 10 & $3,4,9,10,11,12,13,14,15,16$ & .71 \\
Total & 18 & - & .76 \\
\hline
\end{tabular}

Cronbach's alpha for the PSS was .76. There was a standardized instrument for parenting stress, which is the 101-item Parenting Stress Index. However, we used the PSS instead by taking into account Nepal's high illiteracy rate and the lower number of questionnaire items.

\section{4) Psychological Well-Being-Post-Traumatic Changes Questionnaire(PWB-PTCQ)}

It is a standardized instrument comprised of 18 items self-report measure to assess perceived changes in psychological well-being following traumatic events with 6 subscales: Self-acceptance, Autonomy, Purpose in Life, Positive Relations with Others, Environmental Mastery and Personal Growth Orientation. Scores of over 54 indicate the presence of a positive change (Joseph et al., 2012). In this study, the Cronbach's alpha for this instrument was .67.

Table 5. Internal Consistency and Subscales of the PWB-PTCQ

\begin{tabular}{cccc}
\hline Subscales & Number of items & Composition of items & Cronbach's $a$ \\
\hline Self-acceptance & 3 & $1,7,13$ & .60 \\
Autonomy & 3 & $2,8,14$ & .70 \\
Purpose in life & 3 & $3,9,15$ & .62 \\
Positive relations with others & 3 & $4,10,16$ & .68 \\
Environmental mastery & 3 & $5,11,17$ & .60 \\
Personal growth & 3 & $6,12,18$ & .61 \\
Total & 18 & - & .67 \\
\hline
\end{tabular}


Journal of Symbols \& Sandplay Therapy, Vol.8 No.2.

\section{Research Design and Process}

In order to verify the effect of group sandplay therapy on post-traumatic stress symptoms, parenting stress and the psychological well-being of parents, this study conducted group sandplay on the experimental group and implemented a pretest-posttest design while the control group did not receive any therapy.

The 12 parents of the experimental group were divided into two subgroups: 6 in Subgroup A and 6 in Subgroup B. Each sandplay session was divided into three parts: introduction, activity and a wrap-up. First the participants had time to touch sand and engage. Then they engaged in sandplay therapy, after which they shared the content of their sandtrays and their emotions with their partners.

\section{Research Analysis}

The SPSS Statistics V24 statistical program was used to examine the pre-post effects of group sandplay therapy in the experimental group and the control group, and for non-parametric statistics the Wilcoxon test was performed to investigate the difference between the lower factors by scales.

\section{Results}

1. The Effect of Group Sandplay Therapy on Post-Traumatic Stress Symptoms in Child Survivors of the Nepal Earthquake

In the CROPS result for the experimental group, you will see that there was a significant drop in the mean post-test score from the mean pre-test score. Also for PROPS, there was a significant decrease in the mean post-test score for the experimental group. The experimental group's pre-test score of CROPS was fairly high. It was 27.42 points while the cut-off point was 19 or higher, meaning that the children showed fairly high levels of 
Haegi Hwang / The Effect of Parent Group Sandplay Therapy on the Nepal Earthquake Survivors: Post-Traumatic Stress Symptoms, Parenting Stress and Psychological Well-Being of Parents as well as Post-Traumatic Stress Symptoms in Children

Table 6. Difference Verification on Post-Traumatic Stress Symptoms in Child Survivors

\begin{tabular}{|c|c|c|c|c|}
\hline & & $\begin{array}{l}\text { Pre-test } \\
(\mathrm{N}=12)\end{array}$ & $\begin{array}{l}\text { Post-test } \\
(\mathrm{N}=12)\end{array}$ & $Z$ \\
\hline & & $\mathrm{M}(\mathrm{SD})$ & $\mathrm{M}(\mathrm{SD})$ & \\
\hline \multirow{3}{*}{$\begin{array}{c}\text { Report by } \\
\text { child }\end{array}$} & Experimental group & $27.42(7.95)$ & $10.58(2.15)$ & $-3.06^{* * *}$ \\
\hline & Control group & $23.92(3.78)$ & $23.50(4.76)$ & -0.42 \\
\hline & $Z$ & -1.34 & & \\
\hline \multirow{3}{*}{$\begin{array}{c}\text { Report by } \\
\text { parent }\end{array}$} & Experimental group & $23.08(8.75)$ & $10.33(3.03)$ & $-3.06^{* *}$ \\
\hline & Control group & $23.92(3.78)$ & $23.50(4.76)$ & -0.42 \\
\hline & $Z$ & -0.71 & & \\
\hline
\end{tabular}

$* p<.05, * * p<.01$

post-traumatic reactions. However, in the post-test, the score fell to 10.58. As for PROPS, the pre-test score was 23.08 but the score fell to 10.33 after therapy, much lower than the cut-off point of 16. Such results demonstrate that post-traumatic symptoms, both internal and external, in children were reduced after their parents received therapy. In other words, parental group sandplay therapy was effective in reducing post-traumatic symptoms in child survivors of the Nepal earthquake.

\section{The Effect of Group Sandplay Therapy on Post-Traumatic Stress Symptoms in Parent Survivors}

From IES-R in the case of the experimental group, the mean post-test scores for the three subscales of hyperarousal, avoidance and intrusion as well as the total score all underwent a significant reduction. Pre-test total scores of 37 or higher indicate PTSD symptom serious enough to affect the immune system. That the score was 50 prior to therapy indicated that even a year after the incident, parent survivors of the Nepal earthquake still suffered from post-traumatic stress. However, after therapy, the score fell to 24.67. A score of 24 indicates not the existence of PTSD symptoms, but rather the potential for these symptoms. That such a high score fell to a score low enough to indicate lighter symptoms shows that despite the 
Journal of Symbols \& Sandplay Therapy, Vol.8 No.2.

Table 7. Difference Verification on Post-Traumatic Stress Symptoms in Parent Survivors

\begin{tabular}{|c|c|c|c|c|}
\hline & & $\begin{array}{l}\text { Pre-test } \\
(\mathrm{N}=12)\end{array}$ & $\begin{array}{l}\text { Post-test } \\
(\mathrm{N}=12)\end{array}$ & $Z$ \\
\hline & & $\mathrm{M}(\mathrm{SD})$ & $\mathrm{M}(\mathrm{SD})$ & \\
\hline \multirow{3}{*}{ Avoidance } & Experimental group & $17.92(3.42)$ & $8.67(1.87)$ & $-3.07^{* * *}$ \\
\hline & Control group & $18.67(4.12)$ & $17.08(3.70)$ & -1.32 \\
\hline & $Z$ & -0.22 & & \\
\hline \multirow{3}{*}{ Intrusion } & Experimental group & $19.67(3.37)$ & $9.83(3.49)$ & $-3.06^{* *}$ \\
\hline & Control group & $18.67(3.94)$ & $19.67(2.61)$ & -0.59 \\
\hline & $Z$ & -0.67 & & \\
\hline \multirow{3}{*}{ Hyperarousal } & Experimental group & $12.42(4.10)$ & $6.17(1.70)$ & $-3.06^{* *}$ \\
\hline & Control group & $14.08(4.72)$ & $14.08(3.96)$ & -0.54 \\
\hline & $Z$ & -1.07 & & \\
\hline \multirow{3}{*}{ Total } & Experimental group & $50.00(9.49)$ & $24.67(5.96)$ & $-3.06^{* *}$ \\
\hline & Control group & 49.83(10.29) & $50.83(8.73)$ & -0.54 \\
\hline & $Z$ & -0.53 & & \\
\hline
\end{tabular}

${ }^{*} p<.05,{ }^{* *} p<.01$

short intervention, group sandplay therapy was effective in reducing post-traumatic symptoms.

\section{The Effect of Group Sandplay Therapy on Parental Stress of Parent Survivors}

For the experimental group, both positive aspects of parenting, which include items on emotional benefits and personal development, and negative aspects of parenting, which include items on demands on social resources and restrictions, showed a significant decrease in their post-test scores. There was a significant reduction in the total score as well. The result showed that group sandplay had a significant effect in reducing the parenting stress of parent survivors of the Nepal earthquake, in terms of both positive and negative aspects of parenting. 
Haegi Hwang / The Effect of Parent Group Sandplay Therapy on the Nepal Earthquake Survivors: Post-Traumatic Stress Symptoms, Parenting Stress and Psychological Well-Being of Parents as well as Post-Traumatic Stress Symptoms in Children

Table 8. Difference Verification on Parental Stress of Parent Survivors

\begin{tabular}{|c|c|c|c|c|}
\hline & & $\begin{array}{l}\text { Pre-test } \\
(\mathrm{N}=12)\end{array}$ & $\begin{array}{l}\text { Post-test } \\
(\mathrm{N}=12)\end{array}$ & $Z$ \\
\hline & & $\mathrm{M}(\mathrm{SD})$ & $\mathrm{M}(\mathrm{SD})$ & \\
\hline \multirow{3}{*}{$\begin{array}{l}\text { Positive } \\
\text { theme }\end{array}$} & Experimental group & 28.42(1.98) & $16.83(3.10)$ & $-3.07^{*}$ \\
\hline & Control group & $30.58(2.64)$ & $30.42(3.32)$ & -0.36 \\
\hline & $Z$ & -1.79 & & \\
\hline \multirow{3}{*}{$\begin{array}{l}\text { Negative } \\
\text { theme }\end{array}$} & Experimental group & $40.08(2.43)$ & $22.92(5.85)$ & $-3.06^{* *}$ \\
\hline & Control group & $38.25(3.70)$ & $37.33(2.06)$ & -0.85 \\
\hline & $Z$ & -1.13 & & \\
\hline \multirow{3}{*}{ Total } & Experimental group & $65.33(5.33)$ & $39.75(5.17)$ & $-3.06^{* * *}$ \\
\hline & Control group & $68.83(3.95)$ & $68.50(3.09)$ & -0.98 \\
\hline & $Z$ & -1.48 & & \\
\hline
\end{tabular}

${ }^{*} p<.05,{ }^{* *} p<.01$

\section{The Effect of Group Sandplay Therapy on Psychological Well-Being of Parent} Survivors

We also examined the effect of group sandplay therapy on the psychological wellbeing of the parents. PWB-PTCQ has 6 subscales: Acceptance, Autonomy, Purpose in Life, Positive Relations with Others, Environmental Mastery, Personal Growth. The experimental group's mean post-test scores for all of these subscales showed a significant increase. The same could be observed in the total post-test score as well. Scores of over 54 indicate the presence of a positive change. Through the post-test result, we were able to see that group sandplay therapy helped improve the parents' psychological wellbeing. 
Journal of Symbols \& Sandplay Therapy, Vol.8 No.2.

Table 9. Difference Verification on Psychological Well-Being of Parent Survivors

\begin{tabular}{|c|c|c|c|c|}
\hline & & $\begin{array}{l}\text { Pre-test } \\
(\mathrm{N}=12)\end{array}$ & $\begin{array}{l}\text { Post-test } \\
(\mathrm{N}=12)\end{array}$ & $Z$ \\
\hline & & $\mathrm{M}(\mathrm{SD})$ & $\mathrm{M}(\mathrm{SD})$ & \\
\hline \multirow{3}{*}{ Self-acceptance } & Experimental group & $7.33(1.37)$ & $12.08(0.90)$ & $-3.10^{* *}$ \\
\hline & Control group & $7.00(2.49)$ & $6.75(2.38)$ & -0.42 \\
\hline & $Z$ & -0.82 & & \\
\hline \multirow{3}{*}{ Autonomy } & Experimental group & $6.92(2.02)$ & $11.17(1.11)$ & $-2.95^{* *}$ \\
\hline & Control group & $6.33(1.83)$ & $6.17(1.59)$ & -0.10 \\
\hline & $Z$ & -0.75 & & \\
\hline \multirow{3}{*}{$\begin{array}{l}\text { Purpose in } \\
\text { life }\end{array}$} & Experimental group & $6.50(1.68)$ & $11.08(1.38)$ & $-3.09^{* *}$ \\
\hline & Control group & $6.25(1.82)$ & $5.83(1.34)$ & -0.51 \\
\hline & $Z$ & -0.72 & & \\
\hline \multirow{3}{*}{$\begin{array}{l}\text { Positive relations with } \\
\text { others }\end{array}$} & Experimental group & $7.75(1.76)$ & $12.75(0.87)$ & $-3.09^{* *}$ \\
\hline & Control group & $6.42(1.68)$ & $5.42(1.44)$ & -1.25 \\
\hline & $Z$ & -1.66 & & \\
\hline \multirow{3}{*}{$\begin{array}{c}\text { Environmental } \\
\text { mastery }\end{array}$} & Experimental group & $7.00(0.85)$ & $11.33(1.44)$ & $-3.08^{* *}$ \\
\hline & Control group & $6.50(0.80)$ & $6.33(0.89)$ & -0.43 \\
\hline & $Z$ & -1.47 & & \\
\hline \multirow{3}{*}{$\begin{array}{l}\text { Personal } \\
\text { growth }\end{array}$} & Experimental group & $8.42(1.44)$ & $13.00(1.21)$ & $-3.07^{* *}$ \\
\hline & Control group & $6.92(1.88)$ & $6.75(2.18)$ & -0.09 \\
\hline & $Z$ & -1.52 & & \\
\hline \multirow{3}{*}{ Total } & Experimental group & $43.92(5.70)$ & $71.42(3.92)$ & $-3.06^{* *}$ \\
\hline & Control group & $39.42(4.93)$ & $37.25(3.49)$ & -1.60 \\
\hline & $Z$ & -1.68 & & \\
\hline
\end{tabular}

${ }_{\mathrm{p}}^{\mathrm{p}<.05,}{ }^{* *} \mathrm{p}<.01$ 
Haegi Hwang / The Effect of Parent Group Sandplay Therapy on the Nepal Earthquake Survivors: Post-Traumatic Stress Symptoms, Parenting Stress and Psychological Well-Being of Parents as well as Post-Traumatic Stress Symptoms in Children

\section{Discussion}

To summarize the study findings, this study discovered that group sandplay therapy reduced the parenting stress and increased the psychological wellbeing of parent survivors of the Nepal earthquake. Moreover, it found that group sandplay therapy significantly reduced post-traumatic symptoms in both the child and parent survivors.

Many studies involving a group sandplay therapy intervention for child and adolescent survivors of natural disasters have been conducted in Korea and other countries. But there were an insufficient number of studies that made the same type of intervention for parents. This study is therefore meaningful in that it has been able to confirm that the group sandplay therapy approach is effective for parent survivors of earthquakes. What is also meaningful is that the study confirmed that parents' group sandplay therapy is effective in reducing post-traumatic symptoms in their children.

However, in light of the fact that participants in this study were limited to parent survivors residing in a certain part of Nepal, the research results cannot speak for the entire group of earthquake survivors. In addition, only seven sessions of sandplay therapy were administered to the participants, which meant that we were not able to validate the therapy's long-term effects. Therefore, continued research efforts as well as a follow-up validation of the therapy's effects would be needed.

Once its limitations are overcome, group sandplay therapy, together with the development of various psychological therapeutic approaches and programs, could greatly assist both parent and child survivors of unexpected natural disasters, especially earthquakes, to return to their normal lives as soon as possible. This study serves as an objective base for future studies, through which long-term, sustainable sandplay therapy interventions will actively be made in cases of earthquakes. 
Journal of Symbols \& Sandplay Therapy, Vol.8 No.2.

\section{References}

American Psychiatric Association. (2013). Diagnostic and statistical manual of mental disorders, 5th Edition. Arlington, VA: American Psychiatric Association.

Berry, J. O., \& Jones, W. H. (1995). The parental stress scale: Initial psychometric evidence. Journal of Social and Personal Relationships, 12(3), 463-472.

Correia, L., \& Linhares, M. B. M. (2007). Maternal anxiety in the pre- and postnatal period: A literature review. Revista Latino-Americana Enfermagem, 15(4), 677-683.

Greenwald, R., \& Rubin, A. (1999). Assessment of posttraumatic symptoms in children: Development and preliminary validation of parent and child scales. Research on Social Work Practice, $9(1), 61-75$.

Horowitz, M., Wilner, N., \& Alvatez, W. (1979). Impact of event scale: A measure of subjective stress. Psychosomatic Medicine, 41, 209-218.

Joseph, S., Maltby, J., Wood, A. M., Stockton, H., Hunt, N., \& Regel, S. (2012). The Psychological Well-Being-Post-Traumatic Changes Questionnaire(PWB-PTCQ): Reliability and validity. Psychological Trauma Theory, Research, Practice, and Policy, \&4), 420.

Jung, D-Y., \& Choi, J-A. (2010). A Comparative study on psychological well-being of parent of children with and without disabilities. Journal of Emotional \& Behavioral Disorders, 26(3), $319-343$.

Jung, Y-J., \& Kim, Y-J. (2014). The effects of NLP counseling program on parenting stress, psychological well-being, and parenting attitude among mothers: The case of those with preschooler or school-aged children. The Korean Journal of Health Psychology, 192), 485-507.

Kang, I-A., Jang, M-K., Kim, J-K., \& Kim, M-K. (2011). The effect of sandplay therapy on depression and EEG of parents having children in psychotherapy. Korean Journal of Child Welfare, 9(3), 39-60.

Kang, S-U., Kwon, J-S., Lee, H-J., \& Jeon, H-G. (2014). Social security measures for the vulnerable social group during disasters. Korea Institute for Health and Social Affairs.

Lee, K-Y. (2015). Nepalese women migration to Korea and paid work: A case study on marriage migrant women in Gwangju Metropolitan City. Journal of DIASPORA Studies, 
Haegi Hwang / The Effect of Parent Group Sandplay Therapy on the Nepal Earthquake Survivors: Post-Traumatic Stress Symotoms, Parenting Stress and Psychological Well-Being of Parents as well as Post-Traumatic Stress Symptoms in Children

(2), 121-149.

Lopata, H. Z. (1972). Occupation: Housewife. New York: Oxford University Press.

Ministry of Home Affairs DRR Portal (2015). Housing Damage Information. Retrieved from http://drrpotal.gov.np/

Moon, H-J., \& Lee, J-S. (2010). The study of relationships between mothers' parenting style and internal-external control, psychological well-being and depression in early childhood. Journal of Korean Home Management Association, 29(1). 127-138.

Shariff, A. (2009). Ethnic identity and parenting stress in south Asian families: Implications for culturally sensitive counselling. Canadian Journal of Counselling and Psychotherapy, 43(1), $35-46$.

Weiss, D. S. (2007). The impact of event scale-revised. Assessing psychological trauma and PTSD: A practitioner's handbook (2nd ed, pp. 168-189). New York: Guilford Press.

Weiss, D. S., \& Marmar, C. R. (1997). The impact of event scale-revised. In J. P. Wilson \& T. M. Keane (Eds.), Assessing psychological trauma and PTSD (pp. 399-411). New York: Guilford Press.

Received : October 30, 2017

Revised : December 10, 2017

Accepted : Decebmer 17, 2017 